\author{
Каштанова А. А., Ткачева О.Н., Бойцов С.А. \\ ФГБУ “Государственный научно-исследовательский центр профилактической медицины” Минздрава \\ России. Москва, Россия
}

Значение жировой ткани для организма оказалось намного больше,
чем предполагали ранее. Жировая ткань представляет собой
обширный эндокринный орган, значение которого трудно переоце-
нить, его работа влияет на развитие метаболических нарушений,
кардиоваскулярной патологии. В последнее время активно изуча-
ется связь ожирения и состава кишечной микробиоты. Состав
микробиоты различается в зависимости от характера питания,
физической активности, помимо того сама микробиота может вли-
ять на усвоение питательных веществ, проницаемость кишечной
стенки, на аппетит человека. В представленной статье приведены

некоторые механизмы взаимосвязи микробиоты кишечника и ожирения, результаты исследований последних лет.

Ключевые слова: микробиота кишечника, ожирение, короткоцепочечные жирные кислоты, адипокины.

Кардиоваскулярная терапия и профилактика, 2015; 14(5): 83-86

http://dx.doi.org/10.15829/1728-8800-2015-5-83-86

Поступила 22/06-2015

Принята к публикации 29/06-2015

\title{
Gut microbiota and cardiovascular risk factors. Part 2. Gut microbiota and obesity
}

Kashtanova D. A., Tkacheva O. N., Boytsov S.A.

FSBI "State Scientific-Prevention Center of the Prevention Medicine" of the Healthcare Ministry. Moscow, Russia

The importance of adipose tissue is much greater than it has been expected. Adipose tissue is a large endocrine organ, value of which is difficult to overestimate. Its work influences a lot of metabolic disorders, cardiovascular pathology. Recently, there is active research on the relation of obesity and microbiota contents. It is studied depending on the food type, physical activity, and microbiota itself might influence the absorption of nutrients, permeability of the gut wall, and appetites. The article is focused on several mechanisms of interrelation of gut microbiota and obesity, on the results of last years studies.

Key words: gut microbiota, obesity, short-chain fatty acids, adipokines.

Cardiovascular Therapy and Prevention, 2015; 14(5): 83-86

http://dx.doi.org/10.15829/1728-8800-2015-5-83-86

\section{Информация о предыдущей публикации:}

Каштанова Д.А., Ткачева О.Н., Бойцов С.А.

Микробиота кишечника и факторы кардиоваскулярного риска.

Часть 1. Микробиота кишечника, возраст и пол

Кардиоваскулярная терапия и профилактика, 2015; 14(4): 92-95

http://roscardio.ru/ru/archive-ctp/item/576-cardiovascular-therapy-and-prevention-2014-143.html

ВОЗ - Всемирная организация здравоохранения, КЦЖК - короткоцепочечные жирные кислоты, ССЗ - сердечно-сосудистые заболевания, ТЭС - трансэпителиальное электрическое сопротивление, ФА физическая активность, GPR - G-protein coupled receptor (сопряженный с G-белком рецептор), TJP - tight junction proteins.

\section{Введение}

Согласно информации Всемирной организации здравоохранения (ВО3) с 1980г количество людей в мире, страдающих ожирением, увеличилось более чем в 2 раза, в 2014г >39\% людей в возрасте $\geq 18$ лет имели избыточный вес, $13 \%$ - страдали от ожирения [1]. Известно, избыточная масса тела и ожирение являются одним из факторов риска развития сердечно-сосудистых заболеваний (СС3).
Последнее время точка зрения на роль жировой ткани меняется. Если ранее ей отводилась роль накопителя энергии, то с 80x годов, когда было доказано, что адипоциты - место активного метаболизма половых гормонов, жировой ткани стали придавать все большее значение. Секретируемые жировой тканью вещества - адипокины - обладают широким спектром метаболических эффектов и оказывают влияние на эндотелий сосудов,

*Автор, ответственный за переписку (Corresponding author):

Тел.: +7 (916) 393-91-88

e-mail: dr.kashtanova@gmail.com

[Каштанова Д. А. ${ }^{*}$ - аспирант отдела изучения процессов старения и профилактики возраст-ассоциированных заболеваний, Ткачева О. Н. - д.м.н., профессор, руководитель отдела, заместитель директора по научной и лечебной работе, Бойцов С.А. - д.м.н., профессор, директор]. 
центральную нервную систему, поджелудочную железу, печень, скелетную мускулатуру, почки, иммунную систему и др. Ожирение индуцирует неспецифическое хроническое воспаление. Ожирение ассоциировано с повышением уровня С-реактивного белка [2], ускорением скорости оседания эритроцитов [3], повышением уровней цитокинов $[4,5]$. Жировая ткань занимает значительную часть тела человека, и общее количество секретируемых ей адипокинов может в значительной мере влиять на организм. Каждый адипоцит связан с сосудистой сетью, и адипокины попадают в кровоток довольно легко и быстро.

Стремительный прогресс в области секвенирования метагенома (генома микробиоты) вызвал появление в научном мире огромное количество новых сведений о взаимосвязи микробиоты кишечника с различными органами и системами. За последние 10 лет были получены интереснейшие результаты. Оказалось, что усвоение питательных вешеств зависит от состояния микробиоты кишечника, которая переваривает большую часть потребляемой пищи. Таким образом, два организма, потребившие одну и ту же пишу, усвоят разное количество калорий. К тому же микробиота влияет на проницаемость кишечной стенки, а также на аппетит хозяина.

Роль микробиоты кишечника в развитии ожирения

Большое количество исследований было проведено с привлечением экспериментов на животных. Стерильные мыши достоверно имеют меньшую массу тела и меньшую жировую прослойку в сравнении с сородичами с обычной микрофлорой, даже если их держат на диете с высоким содержанием жира и сахара [6], а трансплантация кала от диких мышей стерильным нормализует их массу тела [7]. Таким образом, в отсутствии микрофлоры получение энергетических запасов с пищей существенно падает. В то же время трансплантация микробиоты от мышей с ожирением стерильным мышам приводит к избыточному накоплению жировой клетчатки у мышей-реципиентов [8].

Изменение привычного питания на диету с высоким содержанием жиров ведет к изменению микробиоты, снижению "хороших" бутират-продуцирующих бактерий, в т.ч. Bacteriodes, увеличению числа условно патогенных бактерий, повышению уровня липополисахарида, за чем следует развитие вялотекущего воспаления и ожирения у мышей. А добавление в рацион пребиотика приводит к увеличению количества Bifidobacterium, улучшению толерантности к глюкозе, снижению экспрессии цитокинов жировой тканью [9, 10].

Исследования с участием людей не так многочисленны, и в силу этических аспектов некоторые эксперименты невозможны на людях. При сравнении состава кишечной микробиоты пациентов с ожирением и нормальной массой тела и обнаружили, что у пациентов с ожирением значительно ниже уровень Bacteriodetes, но больше число Firmicutes [11]. В другом исследовании было отмечено существенное снижение разнообразия микробиоты, снижение Bacteriodetes и повышение Actinobacteria у женщин с ожирением в сравнении с женщинами с нормальной массой тела [12]. Стоит отметить, что существуют и совершенно противоположные выводы, сделанные, например, в исследованиях [13], где было отмечено повышение содержания Bacteriodetes у пациентов с избыточной массой тела, или в работе [14], где не было обнаружено достоверных различий в этих филумах у людей с избыточной и нормальной массой тела. Эти противоречия свидетельствуют о необходимости проведения новых, более масштабных научных исследований.

Калорийность пищи может влиять на микробиоту кишечника, хотя оценивать этот показатель довольно сложно, т.к. нормы потребления калорий индивидуальны для каждого человека. Однако в исследовании показано, что, изменение калорийности пищи с 2400 ккал/сут. на 3400 ккал/сут. с одинаковым составом: $24 \%$ белков, $16 \%$ жиров, $60 \%$ углеводов, всего в течение 3 сут. приводит к увеличению количества Firmicutes и снижению Bacteriodetes [15]. Снижение калорийности пищи одновременно ведет к некоторым изменениям микробиоты [16, 17].

Микробиота кишечника и проницаемость кишечной стенки

Важным фактором в развитии ожирения является проницаемость кишечной стенки, которая также связана с состоянием микробиоты [18]. Изменение плотности контактов между эпителиоцитами за счет воздействия на белки плотных контактов (tight junction proteins, TJP) регулирует обмен ионами и молекулами между базолатеральной и апикальной плазматическими мембранами. С повышенной проницаемостью кишечной стенки связано повышение уровня зонулина [19] - белка, влияющего на плотные контакты, - и еще одного участника в развитии ожирения [20] и хронического неспецифического воспаления [21].

In vitro было показано, что заселение эпителия микрофлорой человека приводит к фосфорилированию и повышению регуляции ТЈР [22]. А на крысах было отмечено положительное влияние пробиотиков на проницаемость кишечной стенки [23]. Также и колонизация стерильных мышей и мышей с колитом непатогенными Escherichia coli Nissle приводила к увеличению белков плотных контактов и восстановлению барьерной функции кишечника [24]. Схожий эффект наблюдался и в другом исследовании при применении Lactobacillus plantarum [25]. На людях были получены некоторые резуль- 
таты с увеличением белков плотных контактов и снижением зонулина после применения пробиотиков, но они были немногочисленными и проводились на небольшом количестве испытуемых [26].

Повышение проницаемости кишечной стенки является одним из триггерных факторов развития метаболической эндотоксемии, также ассоциированной с ожирением. Липополисахарид грамотрицательных бактерий (эндотоксин) попадает в кровоток пассивно - через ослабленные связи плотных белковых контактов [27] и активно - связываясь с хиломикронами, и потребление жирной пищи способствует такому механизму развития эндотоксемии [28, 29]. Эндотоксемия поддерживает вялотекущее воспаление в организме, способствует развитию не только ожирения, но и других факторов риска СС3.

Короткоцепочечные жирные кислоты в развитии ожирения

Одним из механизмов влияния на развитие ожирения может быть уровень короткоцепочечных жирных кислот (КЦЖК), продуцируемых некоторыми бактериями. КЦЖК стимулируют выработку лептина адипоцитами у мышей, за счет чего снижается масса жировой ткани [30]. При сверхэкспрессии рецепторов КЦЖК GPR43 (G-protein coupled receptor 43) мыши не прибавляют в весе, даже на диете с высоким содержанием жира, а мыши с недостатком рецепторов к КЦЖК напротив, склонны к ожирению даже при нормальном питании. Активация GPR43 достоверно ассоциирована с липолизом и улучшением метаболизма глюкозы [31]. Стоит отметить, что КЦЖК влияют на проницаемость кишечной стенки. Физиологические концентрации КЦЖК увеличивают трансэпителиальное электрическое сопротивление (ТЭС) и улучшают барьерную функцию кишки, а при сверхпродукции КЦЖК наблюдается абсолютно противоположная картина: снижается ТЭС и нарушается проницаемость эпителия, отмечается цитотоксичное влияние [32, 33].

Микробиота кишечника, физическая активность и аппетит

Разумеется, не только питание, но и физическая активность (ФА) влияет на конституцию человека. В недавно опубликованной работе было доказано, что микробиота физически активных мышей отличается от мышей, которым не приходится много двигаться. Более того, у мышей с высокой ФА отмечается более интенсивная продукция бутирата, лучшее действие пребиотиков и меньшее системное воспаление [34]. На крысах было показано повышение Lactobacillus, Bifidobacterium и B. Coccoides - E. rectale среди животных с высокой ФА, а также увеличение разнообразия микробиоты [35].

Микробиота может влиять на аппетит хозяина. Клетки слизистой оболочки кишки продуцируют пептид YY 3-36, который является анорексигенным, т.е. снижает аппетит. Предполагается, что экспрессия пептида YY 3-36 может стимулироваться связыванием рецепторов GPR41 и GPR43 с ацетатом и пропионатом соответственно (КЦЖК) [36]. Продукцию анорексигенного гормона лептина также связывают с составом микробиоты кишечника, большее содержание Lactococcus, Bifidobacterium и Lactobacillus ассоциировано с более высоким уровнем этого гормона, в то время как Clostridium, Bacteroides и Prevotella - с более низким [35, 37]. Стоит отметить, что обилие Bacteroidetes связано с низким аппетитом, вероятно из-за стимуляции секреции лептина и пептида YY. Преобладание Bacteroidetes связано и со снижением грелина - гормона с хорошо изученным орексигенным действием. А преобладание Firmicutes приводит к повышению уровня грелина, а, следовательно, и аппетита, повышению проницаемости кишечной стенки и инсулинорезистентности [38].

Коррекция ожирения путем воздействия на микробиоту кишечника

Применение антибиотиков на людях не показало реального результата в снижении веса, длительный прием доксициклина и гидроксихлорохина снизил уровень Bacteroidetes и повысил Firmicutes, что в результате привело к еще большему накоплению жировой массы [39].

Прием пре- и пробиотиков дал хорошие результаты. Пребиотики группы лептина увеличивают содержание Bifidobacterium и Faecalibacterium prausnitzii, уменьшают липополисахарид-индуцированную эндотоксемию и системное воспаление у пациентов с ожирением [40]. Применение олигофруктозы у грызунов показало уменьшение жировой массы, улучшение чувствительности к инсулину даже у животных, получавших пищу повышенной калорийности [41]. Потребление фруктоолигосахаридов у людей ведет к повышению глюкагон-подобного пептида-1, снижающего аппетит. Применение пробиотиков Lactobacillus plantarum также ведет к уменьшению жировой ткани, размеров адипоцитов у животных [42]. При применении пробиотика, содержащего Lactobacillus paracasei, L. rhamus и Bifidobacterium animalis, отмечалось уменьшение жировой ткани, снижение инфильтрации макрофагами жировой ткани у мышей, получавших высококалорийную пищу [43]. У людей применение Lactobacillus gasseri также положительно сказывалось на массе тела, уменьшалась висцеральная жировая масса [44], а у пациентов с сахарным диабетом 2 типа и нарушением толерантности к глюкозе потребление Lactobacillus acidophilus улучшало чувствительность к инсулину [45].

Изменение состава микробиоты кишечника ассоциировано с ожирением, и коррекция микробиоты может стать новой мишенью в лечении и профилактике метаболических нарушений. 


\section{Литература}

1. World Health Organization. Global status report on noncommunicable diseases 2014 Geneva: World Health Organization 2014; 280 p.

2. Choi J, Joseph L, Pilote L. Obesity and C-reactive protein in various populations: a systematic review and meta-analysis. Obes Rev 2013; 14(3): 232-44.

3. de Rooij SR, Nijpels G, Nilsson PM, et al. Relationship Between Insulin S., Cardiovascular Disease I. Low-grade chronic inflammation in the relationship between insulin sensitivity and cardiovascular disease (RISC) population: associations with insulin resistance and cardiometabolic risk profile. Diabetes Care 2009; 32(7): 1295-301.

4. Bahceci M, Gokalp D, Bahceci S, et al. The correlation between adiposity and adiponectin, tumor necrosis factor alpha, interleukin- 6 and high sensitivity C-reactive protein levels. Is adipocyte size associated with inflammation in adults? J Endocrinol Invest 2007; 30(3): 210-4

5. Marques-Vidal P, Bochud M, Bastardot F, et al. Association between inflammatory and obesity markers in a Swiss population-based sample (CoLaus Study). Obes Facts 2012; 5(5): 734-44.

6. Ding S, Chi MM, Scull BP, et al. High-fat diet: bacteria interactions promote intestinal inflammation which precedes and correlates with obesity and insulin resistance in mouse. PLoS One 2010; 5(8): e12191.

7. Backhed $F$, Ding $H$, Wang $T$, et al. The gut microbiota as an environmental factor that regulates fat storage. Proc Natl Acad Sci U S A. 2004; 101(44): 15718-23.

8. Turnbaugh PJ, Ley RE, Mahowald MA, et al. An obesity-associated gut microbiome with increased capacity for energy harvest. Nature 2006; 444(7122): 1027-31.

9. Cani PD, Neyrinck AM, Fava F, et al. Selective increases of bifidobacteria in gut microflora improve high-fat-diet-induced diabetes in mice through a mechanism associated with endotoxaemia. Diabetologia 2007; 50(11): 2374-83.

10. Cani PD, Amar J, Iglesias MA, et al. Metabolic endotoxemia initiates obesity and insulin resistance. Diabetes 2007; 56(7): 1761-72.

11. Ley RE, Turnbaugh PJ, Klein S, et al. Microbial ecology: human gut microbes associated with obesity. Nature 2006; 444(7122): 1022-3.

12. Turnbaugh PJ, Hamady M, Yatsunenko T, et al. A core gut microbiome in obese and lean twins. Nature 2009; 457(7228): 480-4.

13. Schwiertz A, Taras D, Schafer K, et al. Microbiota and SCFA in lean and overweight healthy subjects. Obesity (Silver Spring) 2010; 18(1): 190-5.

14. Duncan SH, Lobley GE, Holtrop G, et al. Human colonic microbiota associated with diet, obesity and weight loss. Int J Obes (Lond) 2008; 32(11): 1720-4.

15. Jumpertz R, Le DS, Turnbaugh PJ, et al. Energy-balance studies reveal associations between gut microbes, caloric load, and nutrient absorption in humans. Am J Clin Nutr 2011; 94(1): 58-65.

16. Russell WR, Gratz SW, Duncan SH, et al. High-protein, reduced-carbohydrate weightloss diets promote metabolite profiles likely to be detrimental to colonic health. Am J Clin Nutr 2011; 93(5): 1062-72.

17. David LA, Maurice CF, Carmody RN, et al. Diet rapidly and reproducibly alters the human gut microbiome. Nature 2014; 505(7484): 559-63.

18. de La Serre $C B$, Ellis CL, Lee J, et al. Propensity to high-fat diet-induced obesity in rats is associated with changes in the gut microbiota and gut inflammation. Am J Physiol Gastrointest Liver Physiol 2010; 299(2): G440-8.

19. Drago S, El Asmar R, Di Pierro M, et al. Gliadin, zonulin and gut permeability: Effects on celiac and non-celiac intestinal mucosa and intestinal cell lines. Scand J Gastroenterol 2006; 41(4): 408-19.

20. Moreno-Navarrete JM, Sabater M, Ortega F, et al. Circulating zonulin, a marker of intestinal permeability, is increased in association with obesity-associated insulin resistance. PLoS One 2012; 7(5): e37160.

21. Fasano A. Zonulin and its regulation of intestinal barrier function: the biological doo to inflammation, autoimmunity, and cancer. Physiol Rev 2011; 91(1): 151-75

22. Ewaschuk JB, Diaz $\mathrm{H}$, Meddings $\mathrm{L}$, et al. Secreted bioactive factors from Bifidobacterium infantis enhance epithelial cell barrier function. Am J Physiol Gastrointest Liver Physiol 2008; 295(5): G1025-34.

23. Shen $T Y$, Qin $H L$, Gao ZG, et al. Influences of enteral nutrition combined with probiotics on gut microflora and barrier function of rats with abdominal infection. World J Gastroenterol 2006; 12(27): 4352-8.
24. Ukena SN, Singh A, Dringenberg U, et al. Probiotic Escherichia coli Nissle 1917 inhibits leaky gut by enhancing mucosal integrity. PLoS One 2007; 2(12): e1308

25. Anderson RC, Cookson AL, McNabb WC, et al. Lactobacillus plantarum DSM 2648 is a potential probiotic that enhances intestinal barrier function. FEMS Microbiol Lett 2010; 309(2): 184-92.

26. Lamprecht M, Bogner S, Schippinger G, et al. Probiotic supplementation affects markers of intestinal barrier, oxidation, and inflammation in trained men; a randomized, double-blinded, placebo-controlled trial. J Int Soc Sports Nutr 2012; 9(1): 45.

27. Harris K, Kassis A, Major G, et al. Is the gut microbiota a new factor contributing to obesity and its metabolic disorders? J Obes 2012; 2012. http://www.hindawi.com/ journals/jobe/2012/879151/

28. Ghoshal S, Witta J, Zhong J, et al. Chylomicrons promote intestinal absorption of lipopolysaccharides. J Lipid Res 2009; 50(1): 90-7.

29. Cani PD, Bibiloni R, Knauf $\mathrm{C}$, et al. Changes in gut microbiota control metabolic endotoxemia-induced inflammation in high-fat diet-induced obesity and diabetes in mice. Diabetes 2008; 57(6): 1470-81.

30. Xiong $\mathrm{Y}$, Miyamoto $\mathrm{N}$, Shibata $\mathrm{K}$, et al. Short-chain fatty acids stimulate leptin production in adipocytes through the $\mathrm{G}$ protein-coupled receptor GPR41. Proc Natl Acad Sci U S A 2004; 101(4): 1045-50.

31. Kimura I, Ozawa K, Inoue D, et al. The gut microbiota suppresses insulin-mediated fat accumulation via the short-chain fatty acid receptor GPR43. Nat Commun 2013; 4: 1829.

32. Suzuki T, Yoshida S, Hara H. Physiological concentrations of short-chain fatty acids immediately suppress colonic epithelial permeability. Br J Nutr 2008; 100(2): 297-305.

33. Peng L, He Z, Chen W, et al. Effects of butyrate on intestinal barrier function in a Caco2 cell monolayer model of intestinal barrier. Pediatr Res 2007; 61(1): 37-41.

34. Matsumoto $\mathrm{M}$, Inoue $\mathrm{R}$, Tsukahara $\mathrm{T}$, et al. Voluntary running exercise alters microbiota composition and increases $n$-butyrate concentration in the rat cecum. Biosci Biotechnol Biochem 2008: 72(2): 572-6.

35. Queipo-Ortuno MI, Seoane LM, Murri M, et al. Gut microbiota composition in male rat models under different nutritional status and physical activity and its association with serum leptin and ghrelin levels. PLoS One 2013; 8(5): e65465.

36. Holzer P, Reichmann F, Farzi A. Neuropeptide Y, peptide YY and pancreatic polypeptide in the gut-brain axis. Neuropeptides 2012; 46(6): 261-74.

37. Ravussin Y, Koren $\mathrm{O}$, Spor A, et al. Responses of gut microbiota to diet composition and weight loss in lean and obese mice. Obesity (Silver Spring) 2012; 20(4): 738-47.

38. Parnell JA, Reimer RA. Prebiotic fibres dose-dependently increase satiety hormones and alter Bacteroidetes and Firmicutes in lean and obese JCR:LA-cp rats. Br J Nutr 2012; 107(4): 601-13.

39. Angelakis $\mathrm{E}$, Million $\mathrm{M}$, Kankoe $\mathrm{S}$, et al. Abnormal weight gain and gut microbiota modifications are side effects of long-term doxycycline and hydroxychloroquine treatment. Antimicrob Agents Chemother 2014;58(6): 3342-7.

40. Dewulf EM, Cani PD, Claus SP, et al. Insight into the prebiotic concept: lessons from an exploratory, double blind intervention study with inulin-type fructans in obese women. Gut 2013; 62(8): 1112-21.

41. Everard A, Lazarevic V, Derrien M, et al. Responses of gut microbiota and glucose and lipid metabolism to prebiotics in genetic obese and diet-induced leptin-resistant mice. Diabetes 2011; 60(11): 2775-86.

42. Takemura N, Okubo T, Sonoyama K. Lactobacillus plantarum strain No. 14 reduces adipocyte size in mice fed high-fat diet. Exp Biol Med (Maywood) 2010; 235(7): 849-56.

43. Wang J, Tang $\mathrm{H}$, Zhang $\mathrm{C}$, et al. Modulation of gut microbiota during probioticmediated attenuation of metabolic syndrome in high fat diet-fed mice. ISME J 2015; 9(1): 1-15.

44. Kadooka Y, Sato M, Imaizumi K, et al. Regulation of abdominal adiposity by probiotics (Lactobacillus gasseri SBT2055) in adults with obese tendencies in a randomized controlled trial. Eur J Clin Nutr 2010; 64(6): 636-43.

45. Imani Fooladi AA, Mahmoodzadeh Hosseini H, Nourani MR, et al. Probiotic as a novel treatment strategy against liver disease. Hepat Mon 2013; 13(2): e7521. 